\title{
Legal and Policy Implications of Cloud Computing
}

\author{
Eve Hill \\ Brown Goldstein \& Levy, USA \\ evelhill@gmail.com
}

\begin{abstract}
Cloud computing holds great promise for addressing the barriers that keep people with disabilities, low literacy and aging-related impairments from fully engaging with technology. However, using cloud-based computing to make assistive technology (AT) more widely available also raises legal and policy issues. The Americans with Disabilities Act, United Nations Convention on the Rights of Persons with Disabilities, Communications Act, and other disability rights laws support increased availability of AT. However, what should the balance be between built-in accessibility and cloud-based access? There are also limits to the requirements and coverage of these laws, and issues about the definition of accessibility as technology develops. Copyright and digital rights are potentially implicated by cloud-based AT, as well as privacy and security rights. The needed infrastructure and interoperability of cloudbased AT may raise concerns for technology developers that regulation may stifle innovation or reduce commercial viability.
\end{abstract}

\section{Introduction}

A recent Pew Research Center study indicates that only 54\% of people with disabilities use the internet, compared with $81 \%$ of people without disabilities. Only $41 \%$ of people with disabilities have broadband internet access at home, compared to $69 \%$ of people without disabilities. [Pew Research Center, "Americans living with disability and their technology profile,"1]. Barriers to internet use include income (people with disabilities are nearly twice as likely to be low-income than people without disabilities), education (61\% of people with disabilities have a high school education or less), and age (58\% of people with disabilities are age 50 or older). However, even controlling for these demographic factors, "living with a disability in and of itself is negatively correlated with someone's likelihood to have internet access." [Pew Research Center, "Americans living with disability and their technology profile," 3].

The accessibility (or lack thereof) of the technology, itself, to people with disabilities, as well as people with low literacy and elders, appears to be a significant factor keeping people with disabilities from using the internet, as well as other forms of electronic and information technology (computers, kiosks, social networking, smart phones, etc.). People encounter more and more electronic and information

${ }^{1}$ http://pewinternet.org/Reports/2011/Disability.aspx

C. Stephanidis (Ed.): Universal Access in HCI, Part I, HCII 2011, LNCS 6765, pp. 478 483, 2011.

(C) Springer-Verlag Berlin Heidelberg 2011 
technologies every day - from the ticket dispenser at the bus station, to the computer at the office, to the point of sale device at the drug store, to the digital meter at the parking garage, to the social networking site showing family pictures. As a result, lack of technology accessibility excludes people with disabilities and others from participation in more and more aspects of their communities, forces them to be dependent on others for more and more "special" assistance, and prevents them from developing and joining new (e.g., online) communities.

People with a variety of impairments need to interact with computers, electronic devices, and the internet differently from the average person. People with vision impairments (ranging from low vision to blindness) may need screen information in large print, with high contrast, in different colors, or through audio output. People with vision impairments may need non-visual ways to input information, through audio input, or keyboard controls. People with manual dexterity impairments may need audio input, larger touch-screen buttons, or keyboard controls. People with hearing disabilities may need volume control, hearing aid interaction, and captioning, text, or other visual representations of audible information. People with cognitive impairments may need color-coding, simplified interfaces, simple language, or audio interactions. People often have more than one impairment, resulting in the need for a combination of assistive technologies (AT) and interface preferences. And people's needs change based on the situation.

A variety of AT applications and accessibility features are available, such as those that provide text-to-speech/read-aloud, large print, change the appearance (contrast or color) of screens, audio volume, audio description, speech-to-text/captioning, keyboard and voice controls, are available and constantly improving. New forms of AT and built-in accessibility features, allowing translation of screen information into simplified interfaces, providing color coding, and more, are developing all the time. However, their complexity (to install, setup and use), the need for frequent updates, limitations on the number of devices on which they can be installed, lack of portability, expense, lack of interoperability, and other factors, limit their use. Cloud computing can address some of these issues and make AT and accessibility features more available to more people in more situations.

\section{Disability Rights Laws}

Enacted in 1990, Title III of the Americans with Disabilities Act (ADA) requires places of public accommodation (such as stores, service providers, hotels, and entertainment and recreation venues) to make their programs and services accessible to people with disabilities. [42 U.S.C. $\$ 12181$ et seq.; 28 C.F.R. Part 36] Title II of the ADA requires state and local governments to make their programs, services, and activities accessible. [42 U.S.C. § 12131 et seq.; 28 C.F.R. Part 35] Both laws build on the requirements of Section 504 of the Rehabilitation Act of 1973, [29 U.S.C. $\$ 701$ et seq.] which required accessibility by entities receiving federal financial assistance. Title I of the ADA [42 U.S.C. $§ 12101$ et seq.; 29 C.F.R. $§ 1630$ ], requires employers with 15 or more employees to provide reasonable accommodations to employees with disabilities. Reasonable accommodations may include accessible and assistive technology, as well as technology solutions to other accessibility issues. 
Both the ADA and Section 504 require nondiscrimination, policy modifications, physical accessibility, and "effective communication" of information as necessary to allow people with disabilities to benefit from the goods, services, programs and activities of covered entities. These legal requirements were developed before the wide adoption of the internet and the profusion of electronic and information technologies in all aspects of life.

Over the past decade, questions have arisen about the application of the ADA's application to accessibility of electronic and information technology, including websites, equipment, and devices. [See Blanck, P., "Flattening the (Inaccessible) Cyberworld for People with Disabilities," Assistive Technology Journal - RESNA, 2008 Fall; 20(3):175-80; Blanck, Hill, Siegal \& Waterstone, Disability Civil Rights Law and Policy, 1161-1202, 2008 (Thomson-West)]. Issues include to what extent the websites of public accommodations are covered by the law; to what extent alternative means of providing information (such as staffed telephone lines) can be provided in lieu of accessible websites or electronic and information equipment; the extent to which internet-only entities (without a physical "place") are covered by Title III; and the extent to which electronic and information equipment is required to meet accessibility requirements for communication and what standards should apply.

The Department of Justice's 2010 amended regulations implementing Titles II and III of the ADA, which go into effect March 15, 2011, make clear that accessible electronic and information technology is an auxiliary aid required by the ADA to provide effective communication. [28 C.F.R. $§ 35.104 ; 28$ C.F.R. §36.303] The Department of Justice also recently issued an Advance Notice of Proposed Rulemaking on Accessibility of Web Information and Services Provided by Entities Covered by the ADA, designed, in part, to formalize its interpretation that the ADA requires accessible websites and to develop standards of accessibility for websites. [CRT Docket No. 110; AG Order No. RIN 1190-AA61, 75 Fed. Reg. 43460 (July 26, 2010)] The Department also issued an Advance Notice of Proposed Rulemaking on Equipment and Furniture, including electronic and information equipment, which would develop standards of accessibility for electronic and information equipment, such as kiosks, provided by public accommodations and public entities. [CRT Docket No. 113; AG Order No. RIN 1190-AA64; 75 Fed. Reg. 43452 (July 26, 2010)].

The U.S. government is also subject to Section 508 of the Rehabilitation Act, enacted in 1998, which requires all electronic and information technology purchased, maintained or used by the federal government to meet accessibility standards. Section 508's standards have had ripple effects beyond federal government technology, as some states have adopted the standards [e.g., http://accessibility.gtri.gatech.edu/ sitid/stateLawAtGlance.php] and as agencies implementing Section 504 have used Section 508 standards to assess compliance. [e.g., U.S. Department of Health and Human Services, Guidance for Exchange and Medicaid Information Technology (IT) Systems, Nov. 3, 2010].

Whether as a matter of the requirement to provide effective communication or as part of requirements for newly constructed and altered facilities, public accommodations and public entities are required to provide access to their web-based information and to their services provided via electronic and information technology equipment. Accessibility of web and other electronic and information technology is more timely, effective and efficient than relying on staff (either in person or by 
telephone). Accessibility features and compatibility with AT will, therefore, be required as built-in components. However, cloud-based AT can be an important component of providing on-demand accessibility. It remains to be seen what standards of accessibility will be required, whether based on the international consensus standards representing by the Web Content Accessibility Guidelines of the World Wide Web Consortium's Web Accessibility Initiative [http://www.w3.org/ WAI/intro/wcag.php], or based on the Section 508 standards currently applicable to U.S. government technology.

However, the ADA will not require accessibility for all types of disabilities. The Department of Justice has interpreted the effective communication requirements of the ADA as applying to people with hearing, vision, and speech disabilities, and not to people with cognitive or learning disabilities. As a result, it is not clear that electronic and information technology is required to be accessible to people with cognitive disabilities or what standards are to be applied. In addition, not all entities providing websites and electronic and information technologies are covered by the ADA or Section 504. In particular, manufacturers are not covered as places of public accommodation and, therefore, are not required to manufacture accessible products, even if some of their commercial and institutional customers are required to ensure accessibility. Therefore, many electronic and information devices are developed and manufactured to be inaccessible, forcing covered entities and individuals to provide accessibility on the back-end. Cloud-based AT and accessibility features could be important to fill these gaps in ADA coverage, but the ADA, Section 504, and Section 508 need to be interpreted in ways that allow, facilitate, and regulate the use of cloudbased accessibility technologies.

Cloud-based accessibility features and AT has the potential to help employers accommodate their employees with disabilities more effectively and efficiently than has ever been possible. Cloud-based AT may be more portable, flexible, and costeffective than other accessible technology solutions. However, to what extent employers will be legally required to use the cloud for accessibility solutions, rather than relying on staff-based solutions, remains to be seen.

The United Nations Convention on the Rights of Persons with Disabilities (UNCRPD), signed by 147 countries and ratified by 97, includes significant provisions regarding AT. The United States has signed the UNCRPD and Congress is expected to consider ratification in 2010. Article 9 requires countries to ensure internet access for persons with disabilities, on an equal basis with others by implementing minimum standards \& guidelines for accessibility of services, by ensuring that private entities offering services to the public take accessibility into account, and by promoting access to new information and communication technologies and promoting accessibility at the design stages. Article 21, governing freedom of expression and access to information, covers the right to seek, receive and impart information on an equal basis with others and requires signatories to ensure that public information is provided in accessible formats and in timely manner without additional cost. [Gonnot, Jean-Pierre, "Overview of the New Convention on the Rights of Persons with Disabilities and its Implications for ICTs," in The Accessibility Imperative, at 25 (G3ict, 2007)] These provisions support accessibility of technology, including through cloud-based AT, but the definition of accessibility, 
the types of disabilities covered, and the balance of support for built-in and cloudbased technologies need to be addressed.

\section{Authorship Rights}

International and domestic copyright laws govern authorship rights. U.S. copyright law provides exceptions for certain types of accessible formats. Thus, the Chafee Amendment [17 U.S.C. §121] allows an "authorized entity" to reproduce copyrighted nondramatic literary works in specialized formats for blind people and people with other print disabilities. Questions implicated by cloud-based accessibility include to what extent internet communications constitute "nondramatic literary works," to what extent individuals with cognitive, learning, and other disabilities are covered by the Chafee Amendment, to what extent cloud-based ATs limit themselves to specialized formats as defined by the law, and to what extent cloud-based AT providers must be "authorized" and check eligibility of their consumers in order to provide accessibility features. In addition, exclusion from the copyright permission process for alternative formats is not consistent from country to country.

U.S. "fair use" doctrine may also impact cloud-based AT providers [17 U.S.C. $\S$ 107]. Whether a reproduction constitutes a "fair use" depends on four factors: the purpose and character of the use, including whether such use is of commercial nature or is for nonprofit educational purposes; the nature of the copyrighted work; the amount and substantiality of the portion used in relation to the copyrighted work as a whole; and the effect of the use upon the potential market for, or value of, the copyrighted work. This is an unclear standard and it has not been tested in the accessibility context.

To what extent copyright will impact cloud computing-based accessibility will also be affected by whether the accessible converts or modifies the document and whether a copy is saved in the cloud or on the user's device.

International copyright law will also affect cloud-based accessibility. The Berne Convention, to which the United States is a party, attempts to harmonize national intellectual property laws by establishing minimum standards. It is administered by the World Intellectual Property Organization, which is currently considering proposals to provide copyright exceptions for alternative formats for people with print disabilities. Brazil, Ecuador and Paraguay have submitted a treaty proposal to provide broad exceptions for print disability accessibility, while the United States has submitted a Consensus Document proposing more narrow exceptions, the European Union has proposed a Joint Recommendation, and the African Group has submitted a treaty proposal to extend exceptions beyond disabilities.

Finally, the contracts and licenses between authors and publishers raise potential barriers to the implementation of cloud-based AT and accessibility features. Strict limitations on the rights (e.g. "visual only") conveyed from an author to a publisher, or lack of clarity about who owns the rights to make an audio or other format version will inhibit accessibility. 


\section{Privacy and Security}

Access to cloud-based assistive technology and accessibility features through personalized preference systems, whether through a password-protected url, a USB stick or other memory device, or facial recognition or fingerprinting, raises privacy and security issues. Many people with disabilities are particularly concerned about privacy and security of their disability-related information. Unauthorized or unintentional revelation of disability-related information to third-parties, such as employers or prospective employers, insurance carriers, and others, raises risks of discrimination and prejudice. Revelation of disability-related information to third parties also raises risks of exploitation and abuse for people whose disabilities make them vulnerable. It will be necessary for cloud-based AT providers to address users' concerns that employers, insurance providers, and others whose websites, computers, and devices they access will be able to tell that they are using cloud or other forms of AT.

In the U.S., a web of laws, including the Health Insurance Portability and Accountability Act of 1996 (HIPAA), the ADA, and the Genetic Information Nondiscrimination Act, govern privacy of disability-related information. International privacy and security laws add additional elements and concerns.

\section{Interoperability and Innovation}

A system of cloud-based AT and accessibility features will work best if it is part of a consistent infrastructure with shared development tools and interoperability mechanisms. A cloud-based AT application is no better than a PC-based application if it is only interoperable with a PC. Vendor, platform, service, and content neutrality would support such an infrastructure. Harmonization of standards among countries is also important. Yet the internet has traditionally benefitted from its openness and lack of regulation, allowing levels of creativity not experienced in more regulated environments. Regulations imposing strict interoperability or neutrality requirements will, therefore, likely be challenged as antithetical to the development of technology. The policy balance between interoperability and broad availability, on the one hand, and innovation and remuneration on the other will implicate trade secret, free speech, net neutrality, competition, and other doctrines.

This paper raises, but does not solve, a few of the legal and policy issues that cloud-based AT and accessibility features must address in order to be successful at extending internet and technology access to people with disabilities, literacy, and agerelated impairments. Some of these issues (such as security and privacy and authorship rights) are not unique to cloud-based accessibility, but are shared by other cloud computing systems. However, the risks may be magnified in the disability context. Some of these issues (disability rights law) actually support development and implementation of cloud-based accessibility, if properly addressed. None of these issues argues against development and implementation of cloud-based accessibility systems and they should not be used as barriers or excuses not to move forward. However, development of accessibility in the cloud must take these policy issues into consideration and policy makers must begin to adjust their traditional views of their areas to recognize both disability and accessibility issues generally and cloud computing issues specifically. 